\title{
Correspondence
}

\section{Necrotising entercolitis. Increased incidence in infants receiving nasoduodenal feeding}

Sir,

Beddis and McKenzie ${ }^{1}$ discussed the possible role of nasoduodenal feeding (NDF) in the aetiology of necrotising enterocolitis (NEC). They did not find a significantly higher incidence of NEC in their group of infants fed by NDF compared with those not being fed by NDF. We should like to report our observations.

During a 2-year period (1978-9) we noticed an increased incidence of NEC. The total number of cases with NEC was 34 , representing a rate of 0.94 per hundred admissions, which rose to a peak of 7.5 during the last 5 months of the period. 77 matched control infants were chosen retrospectively among those of similar birthweights and dates of admission. The following factors were compared: birthweight, gestational age, 1- and 5-minute Apgar scores, highest haematocrit, type of formula fed, daily volume and caloric intake, and incidence of respiratory distress, persistent patent ductus arteriosus, mechanical ventilation, sepsis, exchange transfusion, and prevalence and time of indwelling umbilical catheters. No differences were found for any of these parameters between the two groups by Student's $t$ test or the $\%^{2}$ test. However, NDF had been used in $16(47 \%)$ of the patients with NEC, and in $14(18 \%)$ of the matched controls $(\mathrm{P}<0 \cdot 01)$

The number of patients and controls fed by NDF in which this method was used electively - that is without trying other methods first-was similar (14 of 16 in those with NEC were being fed by NDF, and 12 of 14 of the controls were being fed by NDF). That means that only 2 babies in each group had shown a poor tolerance to a previous trial of gastric feeding. NDF was given via a Silastic tube, and the formula continuously administered by a constant flow infusion pump. In each case the position of the tube was confirmed by $x$-ray.

Although NEC has been quoted as a possible complication of NDF, a comparatively greater risk has not been reported. It remains to be determined whether changes in bacterial intestinal microflora in infants with a nasoduodenal tube in place, ${ }^{2}$ which are similar to those found in NEC, ${ }^{3}$ may account for our observations. We suggest that although NDF has a place in the feeding of preterm newborn infants it should not be used as an initial standard method of feeding in nurseries, particularly if NEC is not uncommon.

\section{References}

1 Beddis T, McKenzie S. Transpyloric feeding in the very low birthweight (1500 $\mathrm{g}$ and below) infant. One year's experience in an intensive care neonatal unit. Arch Dis Child 1979; 54: 213-7.

2 Challacombe D. Letter: Bacterial microflora in infants receiving nasojejunal tube feeding. $J$ Pediatr $1974 ; 85$ : 113.

${ }^{3}$ Bell $\mathbf{M} \mathbf{J}$, Feigin $\mathbf{R} \mathrm{D}$, Ternberg $\mathbf{J} \mathbf{L}$, Brotherton $\mathrm{T}$. Evaluation of gastrointestinal microflora in necrotizing enterocolitis. $J$ Pediatr 1978; 92: 589-92.

$$
\begin{array}{r}
\text { C VAzQuez, A Arroyos, } \\
\text { AND A VAlls I Soler } \\
\text { Neonatal Intensive Care Unit, } \\
\text { Department of Paediatrics, } \\
\text { Hospital Infantil de la Seguridad Social, } \\
\text { Plaza Cruces s/n Baracaldo, } \\
\text { Bilbao, Euzkadi, Spain }
\end{array}
$$

Dr McKenzie comments:

The figures presented by Vazquez et al. suggest that during a 2-year period there was an epidemic of NEC in the neonatal unit at a time when the admission rate was much below average (calculated from figures presented). More babies with NEC had been fed by NDF than matched controls without NEC. However, the indications for NDF are not clear; why were more babies of the NEC group fed by NDF despite being of the same birthweight and gestation as the controls? It would also be interesting to know if the increased incidence of NEC during the last 5 months of the study paralleled an increased incidence of NDF.

Although the figures are interesting and it is wise to draw attention to the probable change in upper intestinal flora which may accompany transpyloric intubation, I think that it would be difficult to incriminate NDF in the development of NEC from this retrospective study.

Sheila A McKenzie Department of Paediatrics and Neonatal Medicine, Hammersmith Hospital, Du Cane Road, London W12 OHS

\section{Detection of carbamyl phosphate synthetase 1 deficiency using duodenal biopsy samples}

Sir,

We read with interest the paper by Hoogenraad et al. ${ }^{1}$ and should like to comment on it.

The authors stated that only one case of complete lack of carbamyl phosphate synthetase 1 (CPS 1) had been reported but we can draw their attention to at least 